科 学 通 报

\title{
金刚石中的分子氢*
}

\author{
陈 丰 丁振华 郭九香 薛理辉 叶先贤 \\ (中国科学院地球化学研究所, 贵阳 55000 2) (武汉工业大学测试中心, 武昌 430070)
}

\section{关键词 金刚石、分子虫、相变}

高压下分子氢的相变是 80 年代高压物理和高压化学的热门课题. 但是, 地球深部是否存 在分子氢仍是巨大的悬案. 对此, 本文将提供最近的研究成果.

继发现含钾、钠和铜等氯化物金刚石包体 ${ }^{[1-3]}$ 之后, 作者在辽宁金刚石中发现了分子氢 的拉曼谱峰. 该金刚石无色、菱形十二面体. 吸收光谱测定吸收限为 $300 \mathrm{~nm}$ ，属 Ia 型金刚 石.

Raman 光谱用 Jobin-Yvon 公司的 U-1000 型显微激光 Raman光谱测定,在金刚石内多处发 现 $4190 \mathrm{~cm}^{-1}$ 谱峰 (图 1), 某些部位还有 $3972 \mathrm{~cm}^{-1}$ 侧峰. 为了防止偶然误差, 在相隔数月的时 间内反复测定, 并用丙酮清洗, 均有此峰出现.

由于缺乏大于 $4000 \mathrm{~cm}^{-1}$ 的 Raman 光谱系 统数据, 解释比较困难. 常温常压分子氢的

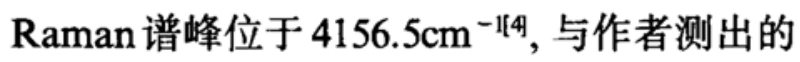
主峰比较接近. 另外, Rossman 提出金属离 子与羟基键有 $4200 \mathrm{~cm}^{-1}$ 峰 ${ }^{[]}$. 但是在显微 Raman 光谱的苂光屏上, 出现 $4190 \mathrm{~cm}^{-1}$ 峰的 部位均未见任何包体; 同时, 谱图上未见到羟 基的主峰. 例如, 常见的在 $35600 \mathrm{~cm}^{-1}$ 附近 的宽峰. 因此, 我们排除了存在 $\mathrm{M}-\mathrm{OH}$ 的 可能性. 认为该峰可能属于分子氢的弯曲振 动, 即 $\Delta V=1, \Delta J=1$ 的谱峰, 式中 $V$ 为振 动量子数, $J$ 为旋转量子数.

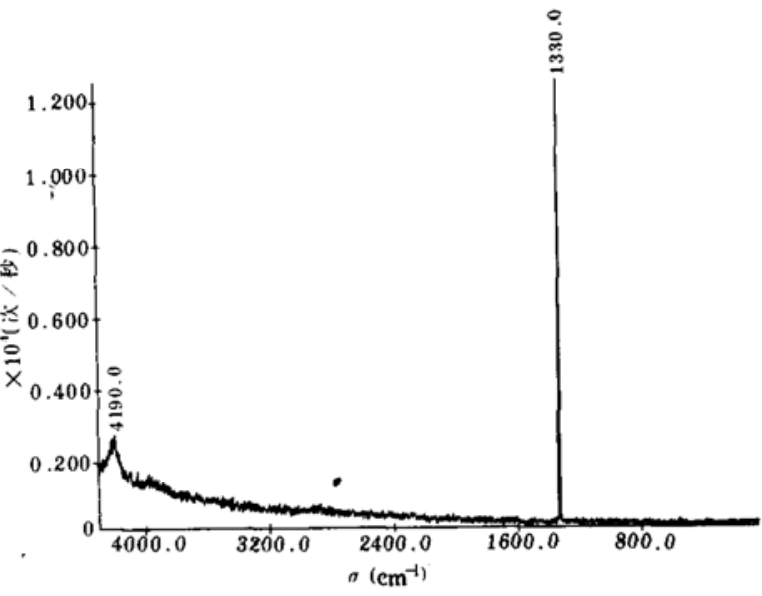

图 1 分子氢的 Raman 光谱

解释中遇到的第一个问题是, 常温常压下气体分子氢的 Raman 谱峰与实测 $4190 \mathrm{~cm}^{-1}$ 峰差值 近 $35 \mathrm{~cm}^{-1}$, 而仪器本身误差小于 $2-3 \mathrm{~cm}^{-1}$. 作者认为谱峰频移是高压造成的. Hemley 和 Mao 报道了随压力变化固态氢的拉曼谱峰的移动 ${ }^{[6}$. 随升压谱峰波数逐渐增到 $4250 \mathrm{~cm}^{-1}$, 然 后持续下降, 经过绝缘体氢到金属氢的相变区后, 波数可降至 $3700 \mathrm{~cm}^{-1}$ 以下. 由此可见, $4190 \mathrm{~cm}^{-1}$ 的谱峰可对应于分子氢的低压区或高压区.

1993-12-10 收稿, 1994-04-01 收修改稿.

* 国家自然科学基金资助项目. 
作者先考虑处于低压区的分子氢的可能性. 利用Silvera 给出的 $5 \mathrm{~K}$ 下 Raman 谱峰和压力的关 系图沉，可得到处于低压区分子氢出现 $4190 \mathrm{~cm}^{-1}$ 峰时压力约为 3-4 GPa. 但通常天然金刚 石形成温度远高于 $5 \mathrm{~K}$. 人工合成高压金刚石的形成温度为 $1300-1600{ }^{\circ} \mathrm{C}$, 用天然金刚石中 的包体计算其形成温度也在 $800-1000{ }^{\circ} \mathrm{C}$ 以上. 迄今为止,我们尚未见到 $800{ }^{\circ} \mathrm{C}$ 以上的高压 相图. 考虑到温度的影响, 我们认为 $3-4 \mathrm{GPa}$ 仅是低压区分子氢的压力下限.

对于高压区分子氢的可能性, 数据更为缺乏. 从 $\mathrm{Mao}$ 和 Hemley 给出的 $500 \mathrm{~K}$ 和 $10^{13} \mathrm{~Pa}$ 的相图潘推测, 与 $4190 \mathrm{~cm}^{-1}$ 对应的低压区分子氢也可能是流体, 即为液相或气相; 对应的高 压 区分子氢则是流体或固相, 尚难判定. 如果高压分子氢为固相, 则可以同时解释另一个 $3792 \mathrm{~cm}^{-1}$ 谱峰. 事实上近于 $3972 \mathrm{~cm}^{-1}$ 主峰的物质极为罕见. Lorenzana ${ }^{19}$ 等, Mao 和 Hemley ${ }^{18}$ 报道了绝缘体氢向金属氢相变区内, 有两个 Raman谱峰, 金属氢为 $3960 \mathrm{~cm}^{-1}$, 绝缘体氢 为 $4100 \mathrm{~cm}^{-1}$. 前一峰接近我们测出的 $3972 \mathrm{~cm}^{-1}$ 峰. 上述测定在 $77 \mathrm{~K}$ 时进行, 如考虑升温会部 分抵消高压对分子氢晶格的压缩, 从而减少拉曼的峰频移, 则我们测出的峰可对应于固态区相 变的两个峰, 那么高压区分子氢形成压力将达 $150 \mathrm{GPa}$ 或更高. Rroff等 (1990) 确证 Ia 型金刚石 可在 $416 \mathrm{GPa}$ 形成, 说明这一压力值是可能的, 但此推测仍需进一步予以证实.

金刚石中的分子氢是首次发现，但金刚石含氢早有报道. Wooks 和 Collins (1983) 综述 了 I 型金刚石中含氢化物的红外光谱, 认为主要是 $\mathrm{C}-\mathrm{H}$ 和 $\mathrm{N}-\mathrm{H}$ 化合物. Guo 等 ${ }^{110}$ 报道 了我国金刚石, 特别是 $\mathbf{I}_{\mathrm{b}}$ 型金刚石中的氢峰. 在氢峰讨论中, Mainwood 和 Stoneham (1984), Briddon 等 (1988) 提出分子氢在金刚石中的稳定问题, 认为它与缺陷相联系可提高其 稳定性.

近年低压下化学气相沉积法合成金刚石薄膜研究证实, 氢在金刚石合成中起着关键的作 用. 如果地球深部含有分子氢, 这对天然金刚石的形成和生长都将有重要意义. 氢的地球化 学研究也将有助于揭示地幔和地核中的许多疑问.

致谢 感谢涂光炽、欧阳自远和张哲儒教授的有益讨论, 以及辽宁省地质六队丛安东和宋 平工程师的大力支持.

\section{参 考 文 献}

[1] 陈丰等,科学通报, $1992,37(10): 921-923$.

[2] 陈丰等,科学通报, 1992,37(1 6): 1489-1491.

[3] 陈丰等,科学通报, 1992, 37(19): 1782- 1784 .

[4] Wopenka, B., Pasteris, J. D., Anal. Chem., 1987, 59 (17): 2165-2170.

[5] Rossman, G. R., Spectroscopic Methods in Mineralog and Geology (ed. Hawthorne, F. C.), Book Crafters Inc., Chelsea, Michigan, 1987, 194.

[6] Hemley, R. J., Mao, H. K., Phys. Rev. Lett., 1988, 61 (7): 857- 860.

[7] Silvera, I. F., Helv. Phys. Acta, 1983, 56(1-3):3-13.

[8] Mao, H. K., Hemley, R. J., Amer. Sci, 1992, 80(5-6): 234-247.

[9] Lorenzana, H. E., Silvera, I. F. et al., Phys. Rev. Lett., 1989, 63 (19): 2080-2083.

[10] Guo, J. G., Chen, F., Cai, X. C. et al., Chinese J. Geochem., 1990, (2): 161 - 168. 